\title{
Diabetic Nephropathy: Fault or Destiny?
}

\author{
T. Deckert and J. E. Poulsen \\ Steno Memorial Hospital, Gentofte, Denmark
}

Summary. Twenty-one young onset Type 1 (insulin dependent) diabetics who developed severe diabetic nephropathy after $14.5 \pm 3.3$ years (mean \pm SD) and 21 age and sex matched Type 1 diabetics without evidence of nephropathy after more than 32 years of disease were compared with particular reference to body build, insulin requirements, stability of diabetes, heart rate and blood pressure before the development of nephropathy. Attempts were made to evaluate the quality of metabolic control during the first 20 years of diabetes from more than 1,600 out-patient measurements of blood and urinary glucose in each group. The renal tubular reabsorption capacity for glucose was calculated in both groups. No differences between the two groups were found for any of the parameters examined, except that the frequency of ketoacidosis was higher in the patients who developed nephropathy. It is concluded that many Type 1 diabetics seem to be protected against the deleterious effect of diabetes on the kidney. The nature of the protecting factors is unknown.

Key words: Diabetic nephropathy, insulin dependent diabetes, blood pressure, metabolic control, stability of diabetes.

Only about $35 \%$ of young onset Type 1 (insulin dependent) diabetics will develop diabetic nephropathy [1]. The other $65 \%$ seem to be protected against the development of clinical nephropathy despite the fact that histological evidence of glomerulosclerosis is seen in nearly all insulin dependent diabetic patients after several years of disease [2,3]. Differences in type of diabetes [4], haemodynamic factors [5] and quality of metabolic control [6] have been claimed as explanations for this discrepancy. Therefore the aim of this paper is to compare the above mentioned factors in two age and sex-matched groups of young onset insulin dependent patients, one group developing severe diabetic nephropathy after 8-22 years of diabetes and another group without clinical evidence of nephropathy after more than 32 years of the disease.

\section{Subjects}

Diabetic nephropathy was defined clinically (but not histologically) as proteinuria of more than $0.5 \mathrm{~g} / 24 \mathrm{~h}$ on more than four different consecutive occasions at least one month apart during one year in insulin dependent diabetics without cardiac failure or renal tract infection. Among 461 insulin dependent diabetics with diabetic nephropathy treated at the Steno Memorial Hospital, all those patients who fulfilled the following criteria were selected: onset of diabetes before the age of 31 years (before 1953) and more than 40 attendances at the out-patient clinic during the first 20 years of diabetes. Only 21 patients ( 9 males and 12 females) fulfilled these criteria.

A control group of patients without diabetic nephropathy was extracted from our cohorts study [7] comprising of 991 insulin dependent diabetics with their onset of diabetes before the age of 31 years and before 1953. Twenty-one patients, who were matched carefully for age at onset, year of onset, sex, area of residence and number of out-patient attendances during the first 20 years of diabetes were selected (Tables 1 and 2). None of the control subjects had developed persistent proteinuria during an observation period of $32-47$ years (mean $38.3 \pm 4.1$ years). Both groups had equal access to treatment and supervision at the Steno Memorial Hospital. None of the patients had proteinuria on the first admission to hospital. The delay between onset of diabetes and the first visit to the Steno Memorial Hospital was 1-9 years in the nephropathy group (mean 2.3 years) and $1-4$ years (mean 1.1 years) in the control group $(p<0.05)$. Most patients were admitted to hospital because of uncontrolled diabetes on several occasions (Table 2). Furthermore, each patient had 40-146 out-patient visits during the first 20 years of diabetes (Table 2). The mean numbers of out-patient visits (57.7) and admissions to hospital (4.2) before persistent proteinuria developed in the nephropathy group were not different from those (62.7 and 4.6 respectively) during the first 
Table 1. Details of the two groups of subjects, one with persistent proteinuria after $14.5 \pm 3.3$ (mean \pm SD) years of diabetes, the other without proteinuria after $>32$ years of diabetes

\begin{tabular}{|c|c|c|c|c|c|c|c|}
\hline & \multirow{2}{*}{$\begin{array}{l}\text { Sex } \\
\text { (male: } \\
\text { female) }\end{array}$} & \multirow{2}{*}{$\begin{array}{l}\text { Age at } \\
\text { onset } \\
\text { (years) }\end{array}$} & \multirow[t]{2}{*}{$\begin{array}{l}\text { Year of } \\
\text { diagnosis }\end{array}$} & \multicolumn{2}{|c|}{$\begin{array}{l}\text { Area of } \\
\text { residence }\end{array}$} & \multirow[t]{2}{*}{$\begin{array}{l}\text { Height } \\
(\mathrm{cm})\end{array}$} & \multirow{2}{*}{$\begin{array}{l}\text { Ideal } \\
\text { body weight } \\
(\%)\end{array}$} \\
\hline & & & & I & II III & & \\
\hline $\begin{array}{l}\text { Subjects with nephropathy } \\
\quad(n=21)\end{array}$ & $9: 12$ & $\begin{array}{l}13.2 \pm 7.6 \\
(1-29)\end{array}$ & $1943 \pm 8$ & 19 & 20 & $167 \pm 6$ & $95.7 \pm 6.3$ \\
\hline $\begin{array}{l}\text { Subjects without nephropathy } \\
\qquad(n=21)\end{array}$ & $9: 12$ & $\begin{array}{l}15.5 \pm 7.6 \\
(2-30)\end{array}$ & $1939 \pm 4$ & 17 & 22 & $169 \pm 9$ & $95.3 \pm 5.7$ \\
\hline
\end{tabular}

Area of residence I: Copenhagen, II: other urban areas in Denmark, III: rural

Values given as mean $\pm \mathrm{SD}$ (range)

Table 2. Details of the two groups of subjects, one with proteinuria after $14.5 \pm 3.3$ (mean $\pm \mathrm{SD}$ ) years of diabetes, the other without proteinuria after $>32$ years of diabetes

\begin{tabular}{|c|c|c|c|c|c|c|c|}
\hline \multirow[b]{2}{*}{. } & \multicolumn{3}{|c|}{ Education } & \multirow{2}{*}{$\begin{array}{l}\text { Out-patient } \\
\text { visits } \\
\text { per patient }{ }^{\mathrm{a}}\end{array}$} & \multirow{2}{*}{$\begin{array}{l}\text { Admissions } \\
\text { to hospital } \\
\text { per patient }\end{array}$} & \multirow{2}{*}{$\begin{array}{l}\text { Hypoglycaemic } \\
\text { coma }\end{array}$} & \multirow[t]{2}{*}{ Ketoacidosis $^{\mathrm{b}}$} \\
\hline & 1 & 2 & 3 & & & & \\
\hline $\begin{array}{l}\text { Subjects with nephropathy } \\
\qquad(n=21)\end{array}$ & 5 & 10 & 6 & $86 \pm 29$ & $\begin{array}{l}5.9 \\
\text { (range: } 1-16 \text { ) }\end{array}$ & $10(19)$ & $10(21)$ \\
\hline $\begin{array}{l}\text { Subjects without nephropathy } \\
\quad(n=21)\end{array}$ & 4 & 12 & 5 & $77 \pm 28$ & $\begin{array}{l}5.4 \\
(1-13)\end{array}$ & $12(25)$ & $3(4)$ \\
\hline
\end{tabular}

Education 1: unskilled worker, 2: skilled worker, 3: academic education

a mean \pm SD

b number of patients (number of episodes)

15 years of diabetes in the control group $(p>0.05)$. Insulin treatment was started at the time of diagnosis in all cases except one, when it was started during the second year of diabetes. All patients were treated with insulin twice a day, except during the first one or two years of diabetes. Protamine insulin or NPH, and soluble insulin were used in every case. The diet prescribed was similar in both groups, consisting of approximately $40 \%$ as carbohydrates, $40 \%$ as fat, and $20 \%$ as protein (as calories). The level of education was similar in the two groups (Table 2) as was their social background (not shown).

Subjects with nephropathy developed this complication 8-22 years after the onset of diabetes (mean $14.5 \pm 3.3$ years). No evidence of other renal diseases appeared. Retinopathy developed in all cases with nephropathy 6-21 years after the onset of diabetes (mean $12.7 \pm 4.0$ years). Seventeen patients developed proliferative retinopathy, all of whom became blind in one or both eyes. The four patients who did not develop proliferative retinopathy had no major visual disturbances despite severe background retinopathy. Nineteen patients in the nephropathy group died in uraemia 20-32 years after the onset of diabetes: 15 from uraemia (serum creatinine $845 \pm 466 \mu \mathrm{mol} / 1$ (mean \pm SD) (normal 55-133 $\mu \mathrm{mol} / \mathrm{l}$ ), two from myocardial infarction (serum creatinine 191 and $121 \mu \mathrm{mol} / \mathrm{l}$ ) and two from cerebral haemorrhage (serum creatinine 330 and $102 \mu \mathrm{mol} / \mathrm{l}$ ). In 12 cases a post mortem histological examination of the kidneys was carried out. In all cases severe nodular glomerulosclerosis was found. Two patients were still alive 29 and 38 years after the onset of diabetes, one with an elevated serum creatinine $(139 \mu \mathrm{mol} / 1)$, the other with normal serum creatinine $(88 \mu \mathrm{mol} / \mathrm{l})$.

In the control group three patients did not develop retinopathy. The remaining 18 patients developed retinopathy
11-34 years after the onset of diabetes (mean 18.8 \pm 6.2 years). Four cases developed severe proliferative changes, of whom three became blind. Another two patients developed sudden severe visual disturbances due to unilateral retinal vein thromboses. Two patients with proliferative retinopathy and two patients without proliferative retinopathy had short periods of intermittent proteinuria $5,15,13$ and 14 years after the onset of diabetes respectively. One patient had severe proteinuria during pregnancy. However, in each case, the proteinuria disappeared. Five patients died $33,34,36,39$ and 44 years after the onset of diabetes. Two patients died from myocardial infarction, one from cardiac failure, one from pneumonia and one from unknown causes. Serum creatinine was normal until death or last follow-up in all cases $(85 \pm 12 \mu \mathrm{mol} / 1$; mean $\pm \mathrm{SD})$ except in one patient, who died in cardiogenic shock with a serum creatinine of $150 \mu \mathrm{mol} / 1$.

\section{Methods}

To characterise differences in the eventual outcome of the diabetes, percentage ideal body weight was calculated on the basis of all body weight and height measurements performed during adult life for each patient. Insulin dose/ $\mathrm{kg}$ body weight was calculated 2, 5, 10,15 and 20 years after diagnosis of diabetes. Calculations were performed only when patients had normal serum creatinine. The degree of instability of diabetes was evaluated from at least 25 blood glucose measurements (range 25-36), performed during the last five days of each admission to hospital under standard conditions, $1-2,3-5,6-10,11-15$ and $16-20$ years after the onset of diabetes. On the basis of these capillary blood glucose measure- 
ments, mean blood glucose and mean amplitude of glycaemic excursions (MAGE) were calculated according to the method of Service et al. [8].

Blood pressure and heart rate were recorded in every case whilst in hospital. Blood pressure was measured with a mercury sphygmomanometer in the supine position after a night's rest. The heart rate was calculated on the basis of four to ten measurements during each hospital admission, performed on the resting patient in the morning. In the nephropathy group, a total of 81 blood pressure measurements were performed before persistent proteinuria had developed. In 12 cases the last blood pressure measurement was performed the year before persistent proteinuria developed and in eight cases 1-12 years before its appearance (mean 2.1 years). In one case no measurement was performed before proteinuria appeared. In the control group 112 blood pressure measurements were performed during the first 20 years of diabetes.

The renal tubular reabsorption capacity for glucose was estimated by comparing mean blood glucose and glucose excretion over the last five days of each hospital admission within the first ten years of diabetes.

The degree of metabolic control during the first 20 years of diabetes was calculated from 1,768 post-prandial capillary blood glucose measurements in the nephropathy group and 1,607 measurements in the control group and 1,749 and 1,591 measurements of $24 \mathrm{~h}$ urinary glucose concentrations and the same numbers of qualitative urinary acetone measurements. The blood glucose measurements were performed at the out-patient clinic $1-2 \mathrm{~h}$ after insulin injection and breakfast. Glucose concentration and acetonuria were measured in a sample of $24 \mathrm{~h}$ urine, collected by the patient the day before visiting the out-patient clinic. Blood and urinary glucose were measured by the reduction method described by Hagedorn et al. [9]. The mean post-prandial blood glucose and the mean percentage of glucose in the $24 \mathrm{~h}$ urine sample were calculated for each patient from all measurements performed during out-patient visits within 2-year periods. Acetonuria was determined by the sodium nitroprusside method of Legal and later by Acetest. Only when the urinary glucose concentration of the same sample exceeded $2.0 \mathrm{~g} / 100 \mathrm{ml}$, was a reaction accepted as positive. Proteinuria was tested for at every out-patient visit. Heller's nitric acid method and later Albustix were used. If the qualitative reaction was positive, a quantiative examination was performed by Tsuchiya's method. Only proteinuria of $\geq 0.5 \mathrm{~g} / 24 \mathrm{~h}$ was accepted as positive. Serum creatinine was determined by the Jaffe method. In addition to blood and urine examinations, the number of hospital admissions for ketoacidosis and/or hypoglycaemic coma was recorded in every case.

Statistical calculations of differences between the two groups were performed by the Wilcoxon rank sum test.

\section{Results}

As can be seen from Table 1, no differences in height or ideal body weight were seen between the two groups. In addition insulin dose $/ \mathrm{kg}$ body weight and the stability of diabetes as expressed by mean blood glucose and MAGE were comparable in the two groups (Fig. 1). The estimations of renal tubular reabsorption capacity for glucose were not significantly different between the two groups, the regression of mean blood glucose in mmol $(y)$ against $24 \mathrm{~h}$ urinary glucose output in $\mathrm{g}(x)$ was $y=0.093 x+$ $7.5, r=0.70, p<0.001$ in the subjects with ne-

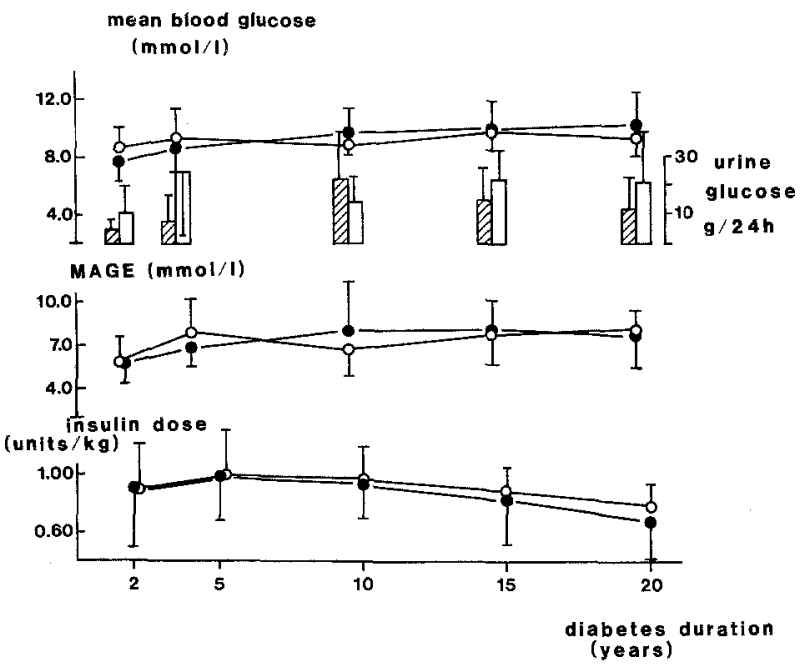

Fig. 1. Mean blood glucose, mean urinary glucose excretion, mean amplitude of glycaemic excursions (MAGE) when in hospital and insulin requirements (for definition see text) as out-patients in 21 Type 1 (insulin dependent) diabetics, with ( and $\square$ ) and 21 without $(O$ and $\square$ ) nephropathy. Mean blood glucose, urinary glucose and MAGE were calculated from measurements during years $1-2$, $3-5,6-10,11-15$ and $16-20$ after the onset of diabetes. Insulin dose was determined at years $2,5,10,15$ and 20 of diabetes. Results expressed as mean \pm SD

phropathy and $y=0.73 x+7.6, r=0.82, p<0.001$ in controls. Thus body build, insulin sensitivity, stability of diabetes and tubular reabsoprtion capacity of glucose did not distinguish the two groups of subjects or predict their outcome. Furthermore blood pressure before the development of nephropathy and heart rate were comparable in the two groups (Fig. 2). There was a slight increase in blood pressure with age in both groups. The increase in heart rate in the group with nephropathy at the end of the period of observation may have been related to the high frequency of uraemia and/or disturbances in the autonomic nervous system in these patients.

Figure 3 shows the results of the out-patient glucose measurements. The post-prandial capillary blood glucose concentration does not seem to indicate any difference in the quality of metabolic control between the two groups. In addition the concentration of glucose and the prevalence of acetonuria in $24 \mathrm{~h}$ urine samples were not different between those with nephropathy and controls. There was no difference in the frequency of hypoglycaemic attacks between the two groups, the nephropathy group having a total of 19 episodes of hypoglycaemic coma while the control group had 25 . The total number of periods of severe ketoacidosis during the first 20 years of diabetes, however, was significantly higher in the nephropathy group, 21 episodes compared with four in the control group $(p<0.01)$ (Table 2). 


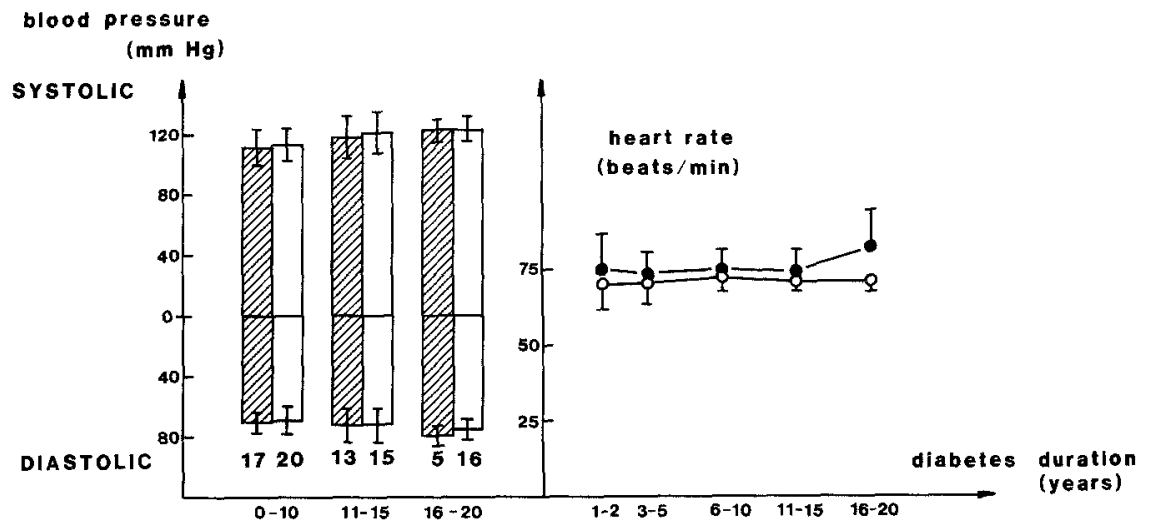

Fig. 2. Blood pressure and heart rate in 21 patients with $(O$ and $\square)$ and 21 patients without nephropathy $(O$ and $\square)$ 0-10, 11-15 and 16-20 years after the onset of diabetes. All measurements in the nephropathy group ( 81 measurements) were performed before persistent proteinuria developed. Heart rate was determined under standardised conditions while in hospital 1-2, 3-5, 6-10, 11-15 and 16-20 years after the onset of diabetes before or after the appearance of proteinuria. Results expressed as mean \pm SD. For comparison of means Wilcoxon's rank sum test was used. The number of patients in the different blood pressure groups is given below the mean diastolic values

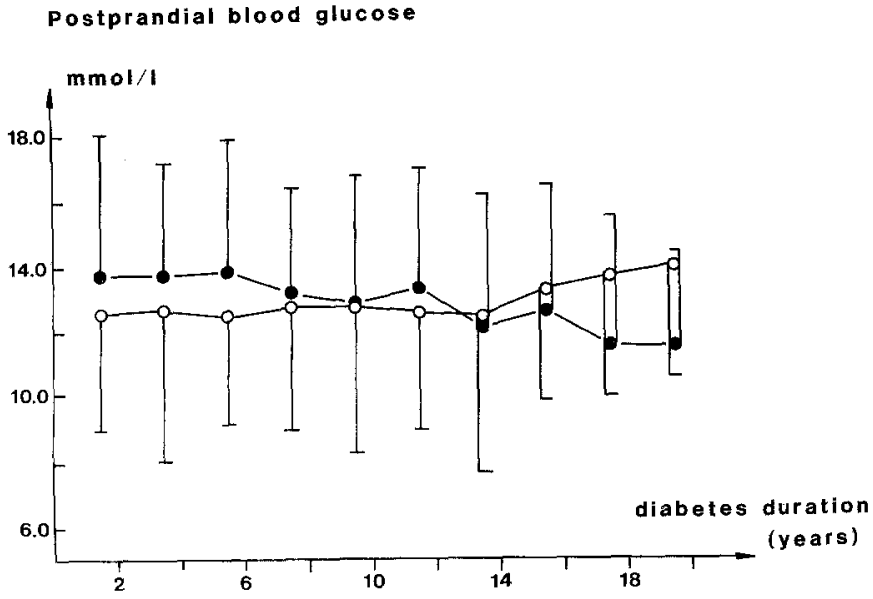

\section{Discussion}

From the onset of insulin dependent diabetes increased renal function and size are seen in all cases [10], particularly during periods of poor metabolic control [11]. In addition an increase in the volume of the mesangial region and in basement membrane thickness in the glomeruli is found in all insulin dependent diabetics two-three years after the onset of diabetes [12]. However, persistent proteinuria only develops in about $35 \%$ of cases. In the present paper a comparison of two age and sex-matched groups of young onset insulin dependent diabetics uniformly treated from the onset of diabetes has been performed. One group developed persistent proteinuria and elevated serum creatinine (except in
Fig. 3. Mean of all post-prandial capillary blood glucose measurements performed in the out-patient clinic on 21 patients with (๑) and 21 patients without nephropathy $(O)$. The measurements were performed during years $1+2,3+4,5+6,7+8,9+10,11+12$, $13+14,15+16,17+18$ and $19+20$ of diabetes. Results expressed as mean \pm SD. The difference between means was tested by Wilcoxon's rank sum test three cases) while the other group did not, despite diabetes of very long duration.

It is not possible to prove that the two groups described here are representative of all our insulin dependent diabetics with and without nephropathy, since the remaining patients with $(n=440)$ and without nephropathy $(n=970)$ were not followed to the same degree as the two groups in this study. A severe bias is however unlikely. A randomised prospective long-term study is impossible to perform because the drop-out rate of young asymptomatic patients is enormous.

Since the risk of developing persistent proteinuria is significantly higher for diabetics who are $0-10$ years old at diagnosis than in patients with a later onset of diabetes [13], it has been suggested that 
Table 3. Prevalence of trace proteinuria in a $24 \mathrm{~h}$ sample

\begin{tabular}{lllll}
\hline $\begin{array}{l}\text { Duration of } \\
\text { diabetes } \\
\text { (years) }\end{array}$ & $\begin{array}{l}\text { Subjects with } \\
\text { nephropathy } \\
(n=21)\end{array}$ & \multicolumn{3}{l}{$\begin{array}{l}\text { Subjects without } \\
\text { nephropathy } \\
(n=21)\end{array}$} \\
\cline { 2 - 5 } & $(n)$ & $(\%)$ & $(n)$ & $(\%)$ \\
\hline $0-5$ & $1 / 366$ & 0.3 & $6 / 591$ & 1.0 \\
$6-10$ & $12 / 435$ & 2.8 & $10 / 443$ & 2.3 \\
$11-15$ & $8 / 165$ & 4.9 & $9 / 276$ & 3.3 \\
$16-20$ & $0 / 20$ & - & $27 / 297$ & 9.1 \\
\hline
\end{tabular}

$n=$ number of all $24 \mathrm{~h}$ urine samples with traces of albumin. Only the results of urine samples collected up to three years before persistent proteinuria developed were recorded

there may be different types of insulin dependent diabetes, one with an early onset which is associated with the antigens HLA-Dw 4 and DR 4 and another with onset around puberty and associated mainly with HLA-Dw 3 and DR 3 [14]. It is possible that the first type is associated with an early and total lack of endogenous insulin secretion and a predisposition to develop nephropathy, while the second type is associated with an insidious onset of B cell insufficiency and a lesser predisposition to develop nephropathy. The present paper does not exclude this possibility although we found no clinical differences between the group with nephropathy and the control subjects, since percentage ideal body weight, insulin requirement $/ \mathrm{kg}$ body weight and MAGE (as an expression of diabetic instability) were identical in the two groups.

Since low blood flow [15] and low blood pressure [16] seem to protect against the development of glomerulosclerosis, it is believed that hypertension and/or high renal blood flow may be important factors in the development of nephropathy. However, in the present study, heart rate and blood pressure were identical in the two groups. Thus the nephropathy in our patients could not be related to these haemodynamic factors. High tubular reabsorption of glucose may lead to an associated high reabsorption of sodium, followed by glomerular hypertension and protein leakage [17]. However, tubular reabsorption of glucose was not significantly higher in the patients with nephropathy compared with the control group. Pirart [6] and others [18] have shown that good metabolic control of diabetes seems to protect against the development of diabetic nephropathy. In accordance with this, we found that the control group had significantly fewer episodes of ketoacidosis during the first 20 years of diabetes than the nephropathy group. However, post-prandial capiallary blood glucose, glycosuria and the prevalence of acetonuria were similar in the two groups. Of course, sporadic post-prandial blood glucose and urinary glucose determinations alone (mean four times a year) cannot give a complete estimation of the degree of metabolic control. However, major differences in control seem to be excluded.

It is possible that those patients, who during a period of poor metabolic control, are particularly prone to increase their GFR and urinary albumin excretion [11] will eventually develop diabetic nephropathy. If this is so, these patients should demonstrate traces of albumin in $24 \mathrm{~h}$ urine samples more frequently than patients who do not ultimately develop nephropathy. However, this does not seem to be the case, as seen from Table 3 , which shows that the prevalence of intermittent proteinuria was not higher in the diabetics who developed nephropathy.

Thus many diabetics seem to be protected against the deleterious effect of diabetes on renal function. The nature of these protecting factors is however unknown, but might be of genetic or immunological origin. We do not believe that diabetic control is irrelevant to the development of nephropathy, but destiny rather than faults in the treatment seem to be of importance in the development of nephropathy in insulin dependent diabetics.

\section{References}

1. Deckert T, Poulsen JE, Larsen M (1978) Prognosis of diabetics with diabetes onset before the age of thirtyone. Diabetologia 14: $363-377$

2. Honey GE, Pryse-Davies J, Roberts DM (1962) A survey of nephropathy in young diabetics. Q J Med N Series 31: $473-483$

3. Thomsen AChr (1965) The kidney in diabetes mellitus. PhD Thesis, Munksgaard, Copenhagen

4. Watkins PJ (1981) Predicting deterioration in renal function. Acta Endocrinol 97 (Suppl 242): 55-56

5. Brenner BM, Hostetter TH, Olson JL, Rennke HG, Venkatachalam MA (1981) The role of glomerular hyperfiltration in the initiation and progression of diabetic nephropathy. Acta Endocrinol 97 (Suppl 242): 7-10

6. Pirart J (1978) Diabetes mellitus and its degenerative complications: A prospective study of 4400 patients observed between 1947 and 1973. Diabetes Care 1: 168-188

7. Deckert T (1980) The influence of supervision and endogenous insulin secretion on the course of insulin-dependent diabetes mellitus. Acta Endocrinol 94: (Suppl 238) 31-38

8. Service FJ, Molnar GD, Rosevar JW, Ackerman E, Gatewood LC, Taylor WR (1970) Mean amplitude of glycemic excursions, a measure of diabetic instability. Diabetes 19: 644-655

9. Hagedorn HC, Halstrøm F, Jensen BN (1946) Swift methods for determination of blood sugar by means of potassium ferricyanide. Reports of the Steno Memorial Hospital, I: 29-44

10. Mogensen CE (1972) Kidney function and glomerular permeability to macromolecules in juvenile diabetes. Dan Med Bull 19: $1-40$

11. Parving H-H, Noer I, Deckert T, Evrin P-E, Nielsen SL, 
Lyngsøe J, Mogensen CE, Rørth M, Svendsen PAa, TrapJensen J, Lassen NA (1976) The effect of metabolic regulation on microvascular permeability to small and large molecules in short-term juvenile diabetics. Diabetologia 12: 161-166

12. Østerby R (1974) Early phases in the development of diabetic glomerulopathy. Acta Med Scand (Suppl 574): 1-82

13. Deckert T, Andersen AR, Christiansen J Sandahl, Andersen JK (1981) The course of diabetic nephropathy. Factors related to development. Acta Endocrinol 97: (Suppl 242): 14-15

14. Platz P, Jakobsen BK, Morling N, Ryder LP. Svejgaard A, Thomsen M, Christy M, Kromann H, Benn J, Nerup J, Green A, Hauge M (1981) HLA-D and -DR antigens in genetic analysis of insulin-dependent diabetes mellitus. Diabetologia (In press)

15. Berkamn J, Rifkin H (1973) Unilateral nodular diabetic glomerulosclerosis (Kimmelstiel-Wilson). Report of a case. Metabolism 22: 715-722

16. Mauer SM, Steffes MW, Azar S, Sandberg SK, Brown DM
(1978) The effects of Goldblatt hypertension on development of the glomerular lesions of diabetes mellitus in the rat. Diabetes 27: 738-744

17. Viberti GC, Haycock GB, Pickup JC, Jarrett RJ, Keen H (1980) Early functional and morphologic vascular renal consequences of the diabetic state. Diabetologia 18: 173-175

18. Rasch R (1979) Prevention of diabetic glomerulopathy in streptozotocin diabetic rats by insulin treatment. Diabetologia 17: $243-248$

Received: 16 January 1981

and in revised form: 12 May 1981

Dr. T. Deckert

Steno Memorial Hospital

DK-2820 Gentofte

Copenhagen, Denmark 